\title{
LIQUID- SOLID AND LIQUID-VAPOR PHASE EQUILIBRIUM IN SECONDARY ALCOHOL - n-ALKANE SYSTEM
}

\author{
Zoya N. Esina ${ }^{a, *}$, Alexander M. Miroshnikov, Margarita R. Korchuganovac
}

\author{
${ }^{a}$ Kemerovo State University, \\ Krasnaya Str. 6, Kemerovo, 650043, Russian Federation \\ ${ }^{\mathrm{b}}$ Kemerovo Institute of Food Science and Technology (University), \\ Stroiteley blvd. 47, Kemerovo, 650056, Russian Federation
}

'MBNOU "City Classical Lyceum", Michurina Str. 19, Kemerovo, 650000, Russian Federation

Received October 12, 2016;

*e-mail: ezn2@rambler.ru

Accepted in revised form June 3, 2017;

Published December 30, 2017

\begin{abstract}
Primary and secondary alcohols, obtained as a product of processing of plant raw materials, can be used as additives in fuel. Mixtures of n-alkanes, cyclic alkanes and aromatic hydrocarbons can act as a model for gasoline and diesel fuel. Therefore, it is necessary to study the characteristics of mixtures of alcohols with normal, cyclic and aromatic hydrocarbons. To simulate liquid-solid and liquid-vapor phase equilibria, a method is used to minimize excess Gibbs energy by the solvation parameter. The authors developed the PCEAS (Phase Charts Eutectic and Azeotropic Systems) software. The input data in the case of constant pressure are the temperature $T^{0}$ and the enthalpy of the phase change $\Delta H^{0}$ of the pure components. Prediction of the thermodynamic parameters of secondary alcohols is used to calculate the eutectic and azeotropic parameters of the secondary alcohol - n-alkane mixture: composition, temperature, melting enthalpy and evaporation. The model makes it possible to determine the average value of the association parameter in the liquid phase $k$. Experimental data for azeotropic mixtures made it possible to establish the association parameter in the vapor phase $\tau$ of the systems under study. The results of calculations can be used to select the optimal composition and obtain the required characteristics of biofuel.
\end{abstract}

Keywords: Biofuel, secondary alcohols, minimization of excess Gibbs energy, eutectic, azeotrope

DOI 10.21603/2500-1418-2017-2-2-33-39

\section{INTRODUCTION}

The study and promotion of new types of biofuels, which use renewable energy sources obtained during the processing of plant raw materials, will contribute to improving the environmental situation and make it possible to reduce the cost of fuel production. Primary and secondary alcohols can be used as additives in fuel, constituting up to $10 \%$ of gasoline and diesel fuel. The properties of these new types of biofuels vary compared to traditional fossil fuels. Mixtures of n-alkanes, cyclic alkanes and aromatic hydrocarbons can act as a model for gasoline and diesel fuel. Therefore, it is necessary to study the characteristics of mixtures of alcohols with normal, cyclic and aromatic hydrocarbons. In [1-6], 1-pentanol and 2-pentanol are considered as oxygen-containing additives to fuel due to such properties as high octane number and high heat of combustion. As the hydrocarbon, $\mathrm{n}$-hexane, cyclohexane or toluene was chosen.

In this paper we study the liquid-solid and liquidvapor phase equilibrium in the secondary alcohol - nalkane system at constant pressure. To simulate liquidsolid and liquid-vapor phase equilibria, a method is used to minimize excess Gibbs energy by the solvation parameter. Eutectic and azeotropic parameters are found in the secondary alcohol - n-alkane binary system: composition, temperature and enthalpy of the phase change, the association parameter in the liquid phase.

To simulate the thermodynamic properties of solutions, it is necessary to calculate the activity coefficients of the mixture components in the liquid and vapor phases. The nonideality of the solution is largely due to the interaction of the molecules. The influence of the nonideality of the solution on the activity coefficients is taken into account by constructing the corresponding thermodynamic models. For alcoholbased polar systems, the following models are used: Van Laar equation, Wilson equation, NRTL, UNIQUAC equation, UNIFAC equation, etc. [7-10]. Most models are not predictive; they require information on the interaction of molecules in binary mixtures.

\section{MATERIALS AND METHODS}

The justification of the Gibbs free energy minimization method according to the solvation parameter is provided in [11]. The solvation parameter $\lambda$ characterizes the ratio of the number of molecules $\mathrm{A}$ to

Please cite this article in press as: Esina Z.N., Miroshnikov A.M., and Korchuganova M.R. Liquid- solid and liquid-vapor phase equilibrium in secondary alcohol - n-alkane system. Science Evolution, 2017, vol. 2, no. 2, pp. 33-39. DOI: 10.21603/2500-1418-2017-2-2-33-39.

Copyright (C) 2017, Esina et al. This is an open access article distributed under the terms of the Creative Commons Attribution 4.0 International License (http:// creativecommons.org/licenses/by/4.0/), allowing third parties to copy and redistribute the material in any medium or format and to remix, transform, and build upon the material for any purpose, even commercially, provided the original work is properly cited and states its license. This article is published with open access at http:// scienceevolution.ru/. 
the number of molecules B in the compound. Based on this method, the PCEAS [12-14] model allowing to calculate activity coefficients and a liquid-solid and liquid-vapor equilibrium with a constant pressure or at a constant temperature, and also the parameters of eutectic and azeotropic points is proposed. The input data in the case of constant pressure are the temperature $T_{i}^{0}$ and the enthalpy of the phase change $\Delta H_{i}^{0}$ of the pure components, $i=1,2$. The model makes it possible to determine the average value of the association parameter in the liquid phase $k$. In this paper, we present the results of the calculation of liquid-solid and liquid-vapor phase diagrams in secondary alcohol - n-alkane systems and water-secondary alcohol using the PCEAS model.

PCEAS model refers to models of the equation of state, is predictive, because it is based only on data on the parameters of pure components and does not use information about the parameters of binary interactions. To construct a mathematical model of the liquid-solid and liquid-vapor phase equilibrium, the method of minimizing the excess free Gibbs energy GE according to the solvation parameter $\lambda[11]$ is applied.

The difference of the equations of state of the binary system for the real and ideal equilibrium phases can be presented in the form [15]:

$$
\left(-H^{E} / R T^{2}\right) d T+\left(V^{E} / R T\right) d P=\Sigma x_{i} d \ln \gamma_{i},
$$

where $H^{E}$ - enthalpy of mixing; $V^{E}$ - excess volume; $P$ - solution pressure; $\gamma_{i}$ - activity coefficient of the $i$-th component; $x_{i}$ - molar fraction of the $i$-th component. In the majority of real solutions, the interaction of components providing the formation of type $\mathrm{AB}$ molecular compounds emerges. The solvation parameter $\lambda=\lambda_{1} / \lambda_{2}$ characterizes the ratio of the number of molecules $\mathrm{A}$ to the number of molecules $\mathrm{B}$ in the compound. The average ratio of the number of molecules of components in solvates characterizes the stable structure of the solution. If solvation of molecules of pure components takes place, the effective molar mass of the component in the solution can be calculated by the formula: $M_{i}^{\prime}=\lambda_{i} M_{i}$, where $M_{i}$ is the molar mass of the component before mixing. For the real systems in which the formation of the molecular compounds called solvates is possible it is necessary to make a transition to effective mole fractions in the equation (1). The effective mole fractions of the components of the binary mixture are calculated by the formulas: $z_{1}=x_{1} /\left(x_{1}+\lambda x_{2}\right), z_{2}=x_{2} /\left(x_{1} /\right.$ $\lambda+x_{2}$ ) [14]. The partial activity coefficients at constant pressure can be represented as:

$$
\ln \gamma_{i}=\Delta H_{i}^{0}\left(1-T_{i}^{0} / T\right) /\left(R T_{i}^{0}\right)-\ln z_{i}+\ln F_{i}\left(z_{i}\right),
$$

where $\Delta H_{i}^{0}$ is the enthalpy of the phase transition of the pure $i$-th component; $F_{i}\left(z_{i}\right)$ is an arbitrary function of the composition; $T_{i}^{0}$ - phase change temperature of the pure $i$-th component, $i=1,2$.

For a small range of boiling points, the excess free Gibbs energy:

$$
\begin{gathered}
G^{E}=z_{1} \Delta \mathrm{H}_{1}^{0}\left(T / T_{1}^{0}-1\right)+z_{2} \Delta \mathrm{H}_{2}^{0}\left(T / T_{2}^{0}-1\right)- \\
-R T\left(z_{1} \ln z_{1}+z_{2} \ln z_{2}\right)+F\left(z_{1}\right) .
\end{gathered}
$$

Here $\mathrm{F}\left(z_{1}\right)=z_{1} F_{1}\left(z_{1}\right)+\left(1-z_{1}\right) F_{2}\left(z_{1}\right)-$ is a function that is chosen from the condition of thermodynamic consistency of the model by the method of Herington and Redlich-Kister [15]. According to this method, the areas limited by the curve $\lg \gamma_{1} / \gamma_{2}$ and the axes of coordinates must be equal. The minimization of excess energy (2) according to the internal parameter $\lambda$ provides the Bernoulli equation:

$$
d T / d z_{1}+f_{1}\left(z_{1}\right) T=f_{2}\left(z_{1}\right) T^{2},
$$

where

$$
\begin{gathered}
f_{1}\left(z_{1}\right)=\alpha /\left(\Delta H_{1}{ }^{0} / R-\alpha z_{1}\right), f_{2}\left(z_{1}\right)= \\
=-\left(\beta+\ln \left(1-z_{1}\right) / z_{1}\right) /\left(\Delta H_{1}{ }^{0} / R-\alpha z_{1}\right), \\
\alpha=\left(\Delta H_{l}{ }^{0}-\Delta H_{2}{ }^{0}\right) / R, \beta=\Delta H_{2}^{0} / R T_{2}^{0}-\Delta H_{l}{ }^{0} / R T_{l}{ }^{0} .
\end{gathered}
$$

The solution of the equation (3) is written as:

$$
\begin{gathered}
T\left(z_{1}\right)=\left[\Delta H_{1}^{0} z_{1}+\Delta H_{2}^{0}\left(1-z_{1}\right)\right] /\left[\Delta H_{1}^{0} z_{1} / T_{1}^{0}+\right. \\
\left.+\Delta H_{2}^{0}\left(1-z_{1}\right) / T_{2}^{0}-R\left(z_{1} \ln z_{1}+\left(1-z_{1}\right) \ln \left(1-z_{1}\right)\right)\right],
\end{gathered}
$$

where $T\left(z_{1}\right)$ is the solution phase change temperature.

The molecules of the components $A$ and $B$ can also form the clusters consisting of molecules of the same type. We will characterize the relation of the number of molecules of the component $A$ to the number of molecules of the component $B$ aggregated into associates in the liquid phase using the association parameter $k=k_{1} / k_{2}$. The coefficient $k_{1}$ shows how many molecules of component $A$ in the liquid phase were combined into a cluster of type $A A$, the coefficient $k_{2}$ shows how many molecules of component $B$ in the liquid phase were combined into a cluster of type $B B$. Similarly, for the association characteristic in the pair, the parameter $\tau=\tau_{1} / \tau_{2}$ is introduced.

To calculate the liquid-solid and liquid-vapor phase equilibria, the thermodynamic coordination of the activity coefficients in the liquid and vapor phases is of particular importance. The solvation parameter $\lambda=\lambda_{1} / \lambda_{2}$, as well as the association parameters in the liquid phase $k=k_{1} / k_{2}$, can be determined by checking the thermodynamic consistency of the activity coefficients of the components by the method of Herington and Redlich-Kister [15]. If $n$ eutectics or azeotropes with close phase change temperatures are formed, their parameters must be averaged. The statistical method for determining the average parameters was proposed by Gibbs in 1901. The average temperature, composition and enthalpy of the phase change are determined by the formula:

$$
\bar{X}=\sum_{j=1}^{n} X_{j} e^{-\frac{\Delta H_{j}}{R T_{j}}} / \sum_{j=1}^{n} e^{-\frac{\Delta H_{j}}{R T_{j}}}
$$

where $X_{j}$ is the solvation parameter, the association coefficient, the eutectic temperature or the azeotrope $\left(T_{j}\right)$, the mole fraction of the binary mixture component in the eutectic or azeotropic point $\left(x_{j}\right)$ and the enthalpy of the phase change $\Delta H_{j}$, and $n$ is the number of eutectics or azeotropes in the system. 
To calculate the average characteristics of a binary mixture, the initial value of the solution temperature in a eutectic or azeotrope $T^{0}$ is introduced, which is close to the experimental one, and the error $\Delta T$ with which the temperature is determined in the range from $T^{0}-\Delta T$ to $T^{0}+\Delta T$. In this range, possible eutectics or azeotropes with temperature $T_{j}$ and the molar enthalpy of the phase change $\Delta H_{j}(j=1,2, \ldots, n)$ are determined in this system.

Table. Eutectic and azeotropic parameters are found in the secondary alcohol $-n$-alkane binary system

\begin{tabular}{|c|c|c|c|c|c|c|c|c|c|}
\hline System & $\begin{array}{c}x_{1 \text { eut, }} \text { mas. } \\
\text { calc. }\end{array}$ & $\begin{array}{l}t_{\text {eut, }}{ }^{\circ} \mathrm{C} \\
\text { calc. }\end{array}$ & $\begin{array}{c}\Delta H_{\text {eut }}, \\
\mathrm{J} / \mathrm{mol}\end{array}$ & $\begin{array}{c}x_{1 \mathrm{az}} \text {, mas. } \\
\text { calc. }\end{array}$ & $\begin{array}{l}t_{\mathrm{az},}{ }^{\circ} \mathrm{C} \\
\text { calc. }\end{array}$ & $\begin{array}{l}\Delta H_{a z}, \\
\mathrm{~J} / \mathrm{mol}\end{array}$ & $\begin{array}{l}x_{1 \mathrm{az}}, \text { mas. } \\
\text { exp. }[16]\end{array}$ & $\begin{array}{c}t_{\mathrm{az},}{ }^{\circ} \mathrm{C} \\
\exp .[16]\end{array}$ & $k_{1} / k_{2}$ \\
\hline $\begin{array}{l}\text { 2-Propanol * } \\
\text { Pentane }\end{array}$ & 0.127 & -136.53 & 7491 & 0.014 & 35.79 & 52068 & 0.060 & 35.50 & $5 / 12$ \\
\hline $\begin{array}{l}\text { 2-Propanol * } \\
\text { Hexane }\end{array}$ & 0.520 & -112.12 & 8404 & 0.182 & 64.56 & 67448 & 0.230 & 62.70 & $30 / 29$ \\
\hline $\begin{array}{l}\text { 2-Propanol * } \\
\text { Heptane }\end{array}$ & 0.569 & -109.05 & 8395 & 0.584 & 77.80 & 75069 & 0.505 & 76.40 & $6 / 5$ \\
\hline $\begin{array}{l}\text { 2-Propanol * } \\
\text { Octane }\end{array}$ & 0.965 & -93.56 & 7050 & 0.867 & 81.38 & 79191 & 0.840 & 81.60 & $9 / 2$ \\
\hline $\begin{array}{l}\text { 2-Butanol* } \\
\text { Pentane }\end{array}$ & 0.217 & -137.21 & 8599 & not az. & not az. & not az. & not az. & not az. & $4 / 7$ \\
\hline $\begin{array}{l}\text { 2-Butanol* } \\
\text { Hexane }\end{array}$ & 0.875 & -120.56 & 10152 & 0.073 & 67.42 & 64982 & 0.080 & 67.20 & $5 / 2$ \\
\hline $\begin{array}{l}\text { 2-Butanol* } \\
\text { Heptane }\end{array}$ & 0.918 & -119.12 & 9884 & 0.367 & 88.26 & 71396 & 0.380 & 89.00 & $10 / 3$ \\
\hline $\begin{array}{l}\text { 2-Butanol* } \\
\text { Octane }\end{array}$ & 0.999 & -114.98 & 9191 & not az. & not az. & not az. & - & - & $27 / 1$ \\
\hline $\begin{array}{l}\text { 2-Pentanol* } \\
\text { Pentane }\end{array}$ & 0.142 & -135.78 & 7963 & not az. & not az. & not az. & - & - & $3 / 8$ \\
\hline $\begin{array}{l}\text { 2-Pentanol* } \\
\text { Hexane }\end{array}$ & 0.624 & -112.89 & 9152 & 0.024 & 68.38 & 63921 & not az. & not az. & $8 / 7$ \\
\hline $\begin{array}{l}\text { 2-Pentanol* } \\
\text { Heptane }\end{array}$ & 0.723 & -110.23 & 9141 & 0.170 & 94.69 & 66978 & 0.15 & 96.00 & $13 / 9$ \\
\hline $\begin{array}{l}\text { 2-Pentanol* } \\
\text { Octane }\end{array}$ & 0.989 & -98.62 & 7640 & 0.500 & 110.29 & 76367 & 0.56 & 114.8 & $8 / 1$ \\
\hline $\begin{array}{l}\text { 2-Hexanol* } \\
\text { Pentane }\end{array}$ & 0.002 & -130.38 & 8606 & not az. & not az. & not az. & - & - & $1 / 18$ \\
\hline $\begin{array}{l}\text { 2-Hexanol* } \\
\text { Hexane }\end{array}$ & 0.155 & -101.35 & 13595 & not az. & not az. & not az. & - & - & $3 / 7$ \\
\hline $\begin{array}{l}\text { 2-Hexanol* } \\
\text { Heptane }\end{array}$ & 0.219 & -97.99 & 14388 & 0.055 & 97.45 & 64588 & - & - & $4 / 7$ \\
\hline $\begin{array}{l}\text { 2-Hexanol* } \\
\text { Octane }\end{array}$ & 0.894 & -81.87 & 16375 & 0.239 & 119.96 & 73013 & - & - & $8 / 3$ \\
\hline $\begin{array}{l}\text { 2-Heptanol* } \\
\text { Pentane }\end{array}$ & 0.244 & -136.67 & 8195 & not az. & not az. & not az. & - & - & $7 / 15$ \\
\hline $\begin{array}{l}\text { 2-Heptanol* } \\
\text { Hexane }\end{array}$ & 0.850 & -117.04 & 9281 & not az. & not az. & not az. & - & - & $9 / 4$ \\
\hline $\begin{array}{l}\text { 2-Heptanol* } \\
\text { Heptane }\end{array}$ & 0.893 & -115.06 & 9226 & 0.021 & 98.12. & 63850 & - & - & $9 / 4$ \\
\hline $\begin{array}{l}\text { 2-Heptanol** } \\
\text { Octane }\end{array}$ & 0.973 & -108.17 & 8077 & 0.110 & 123.46 & 70723 & - & - & $17 / 1$ \\
\hline $\begin{array}{l}\text { 2-Octanol * } \\
\text { Pentane }\end{array}$ & not eut. & not eut. & not eut. & not az. & not az. & not az. & - & - & - \\
\hline $\begin{array}{l}\text { 2-Octanol * } \\
\text { Hexane }\end{array}$ & 0.002 & -95.85 & 13262 & 0.033 & 68.74 & 63488 & - & - & $1 / 21$ \\
\hline $\begin{array}{l}\text { 2-Octanol * } \\
\text { Heptane }\end{array}$ & 0.003 & -91.26 & 14319 & 0.091 & 95.78 & 32626. & - & - & $1 / 17$ \\
\hline $\begin{array}{l}\text { 2-Octanol * } \\
\text { Octane }\end{array}$ & 0.151 & -62.41 & 21166 & 0.046 & 124.85 & 69686 & - & - & $3 / 7$ \\
\hline
\end{tabular}

The mean relative error of azeotropic parameters: $\delta_{T}=0.86 \% ; \delta_{x}=6.98 \%$.

Note. * refers to the calculations of eutectic and azeotropic parameters based on the results of the prediction of the melting enthalpy and the enthalpy of evaporation of secondary alcohols, formulas $(4,5)$. 
The equation of the melting enthalpy model for secondary alcohols:

$$
\begin{gathered}
\Delta H_{\text {melt }}=\frac{(N+1) M T_{\text {melt }}}{1.85 N}+520 N(-1)^{N}-3800 / N, \\
\sigma_{H_{\text {melt }}}=173, \delta_{H_{\text {melt }}}=1.36 \% .
\end{gathered}
$$

The mean square deviation $\sigma_{X}$ and the mean relative error $\delta_{X}$ of the value $X$ are calculated using the formulas:

$$
\begin{gathered}
\sigma_{X}=\sqrt{\frac{\sum_{j=1}^{m}\left(X_{j}^{\text {exp }}-X_{j}^{\mathrm{mod}}\right)^{2}}{m-1},} \\
\delta_{X}=\sum_{j=1}^{m}\left(\frac{\left|X_{j}^{\exp }-X_{j}^{\mathrm{mod}}\right|}{m X_{j}^{\exp }}\right) \cdot 100 \%,
\end{gathered}
$$

Where $X_{j}$ is the enthalpy or temperature of phase transition; $j=1,2, \ldots, m ; m$ is the number of experimental data.

The predictive model for the vaporization enthalpy based on the data on the critical temperature:

$$
\begin{gathered}
\Delta H_{\text {vap }}=\frac{4 M T_{c}}{N+0.47}+(-1)^{N} \cdot 210+5010, \\
\sigma_{H_{v a p}}=211, \delta_{H_{v a p}}=0.31 \% .
\end{gathered}
$$

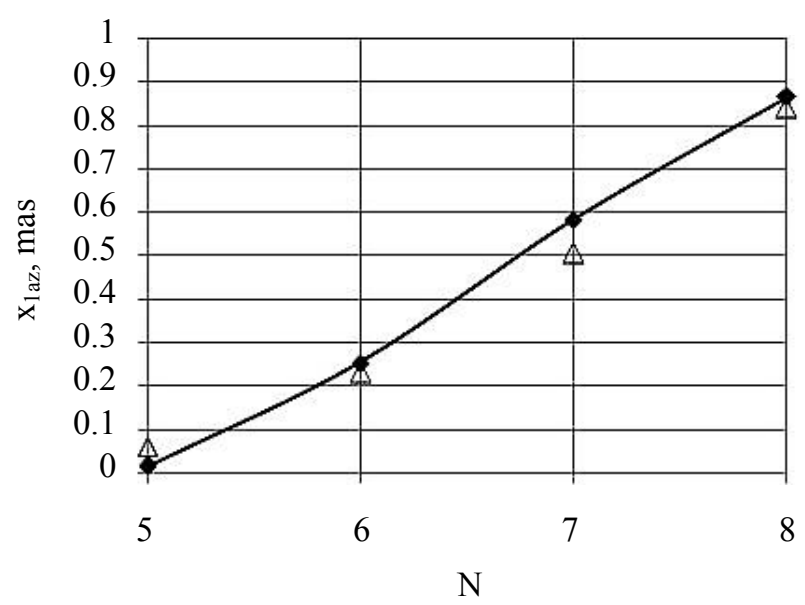

Fig. 1. Dependence of the composition of the first component in the azeotropic point of the 2-propanol $\mathrm{n}$-alkane system on the number of carbon atoms in the n-alkane molecule: series $1(\diamond)$ - experiment [16]; series $2(\Delta)$ - calculation.

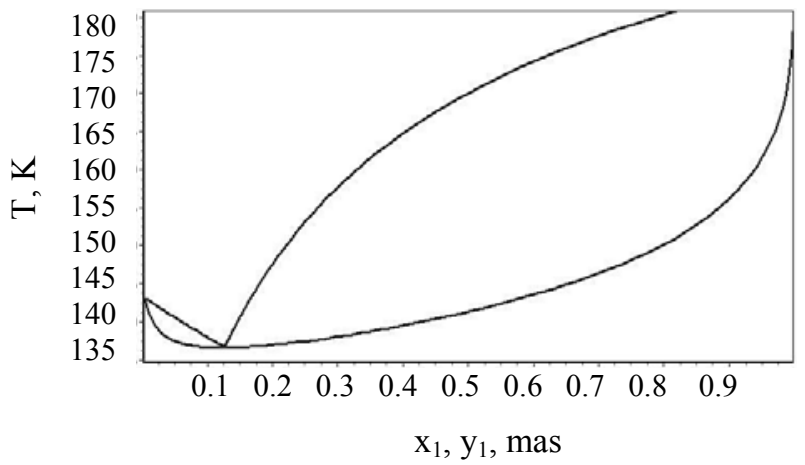

Fig. 3a. Liquid-solid phase diagram of 2-propanol* pentane system.

\section{RESULTS AND DISCUSSION}

The result of this work is the calculation of the liquid-solid and liquid-vapor phase equilibrium in the secondary alcohol - n-alkane system. The liquid-solid and liquid-vapor phase equilibrium in binary systems containing secondary alcohol was calculated using the PCEAS software $[13 ; 14]$.

The table presents the results of calculating the composition and temperature in eutectic and azeotropic points of binary secondary alcohol $-n$-alkane systems, the enthalpy of the phase change, the association parameter in the liquid phase, and experimental data on the composition and temperature at azeotropic points [16].

Experimental data for azeotropic mixtures [16] allowed to establish the association parameter in the vapor phase for all systems presented in the table: $\tau=\tau_{1} / \tau_{2}=\left(k_{1} / 2\right) /\left(k_{2} / 2\right)$. The phase equilibria, taking into account the association and solvation of the molecules, were studied at normal atmospheric pressure.

Fig. 1 shows the dependence of the composition of the first component in the azeotropic point of the 2-propanol - alkane system on the number of carbon atoms in the molecule.

Fig. 2 shows the dependence of the temperature in the azeotropic point of the 2-propanol - n-alkane system on the number of carbon atoms in the molecule.

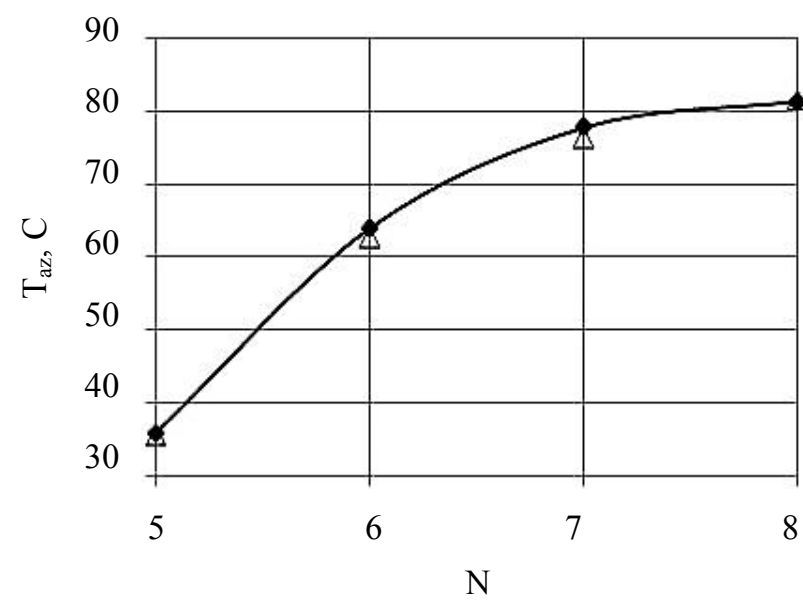

Fig. 2. Dependence of the temperature in the azeotropic point of the 2-propanol-n-alkane system on the number of carbon atoms in the n-alkane molecule: series

$1(\diamond)$ - experiment [16]; series $2(\Delta)$ - calculation.

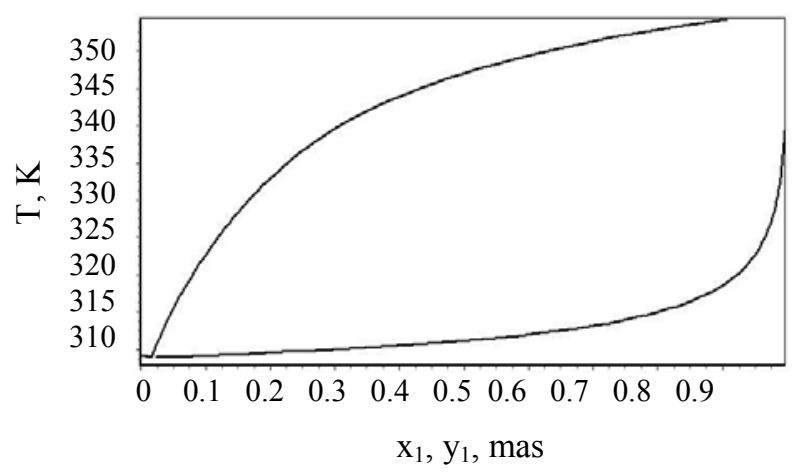

Fig. 3b. Liquid-vapor phase diagram of 2-propanol* pentane system. 
Fig. 3-4 shows liquid-solid and liquid-vapor phase diagrams of the system 2-propanol* - pentane and 2-propanol* - hexane at a pressure of $0.101 \mathrm{MPa}$.

Fig. 5 shows liquid-solid and liquid-vapor phase diagrams of the 2-butanol* - hexane system at a pressure of $0.101 \mathrm{MPa}$.

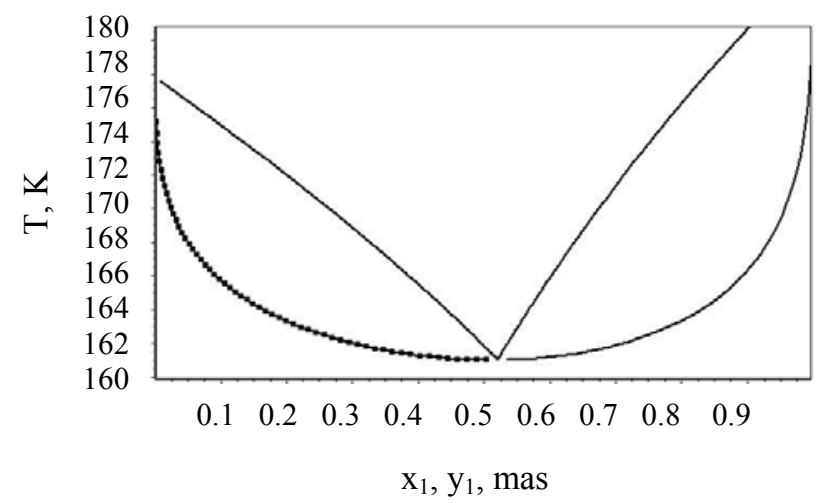

Fig. 4a. Liquid-solid phase diagram of 2-propanol* hexane system.

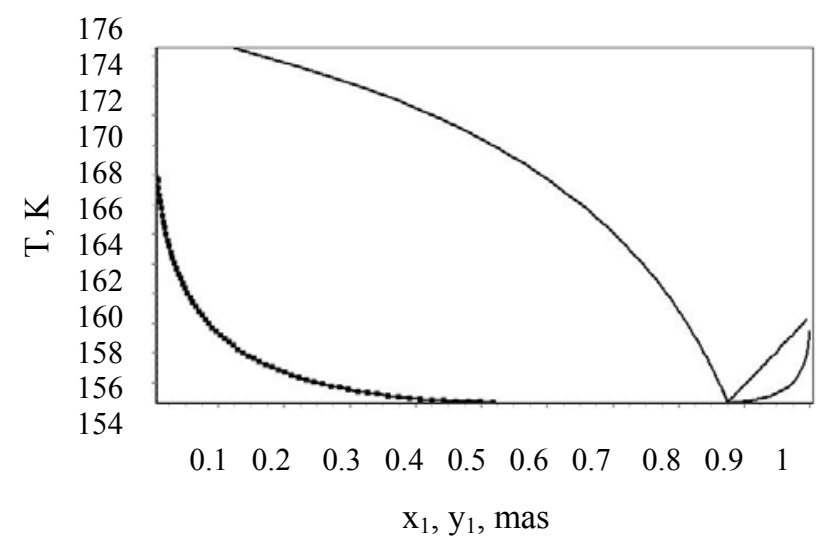

Fig. 5a. Liquid-solid phase diagram of 2-butanol*_ hexane system.

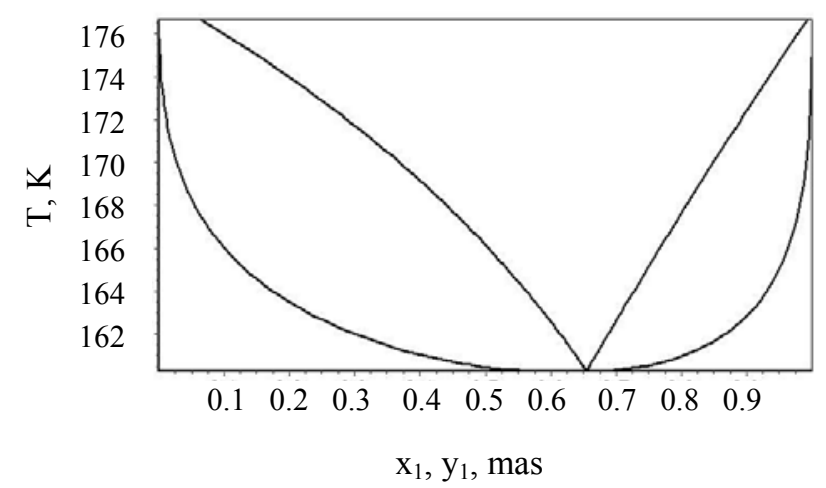

Fig. 6a. Liquid-solid phase diagram of 2-pentanol* - hexane system.
Fig. 6 shows liquid-solid and liquid-vapor phase diagrams of the 2-pentanol* - hexane system at a pressure of $0.101 \mathrm{MPa}$.

Fig. 7 shows liquid-solid and liquid-vapor phase diagrams of the 2-octanol* - octane system at a pressure of $0.101 \mathrm{MPa}$.

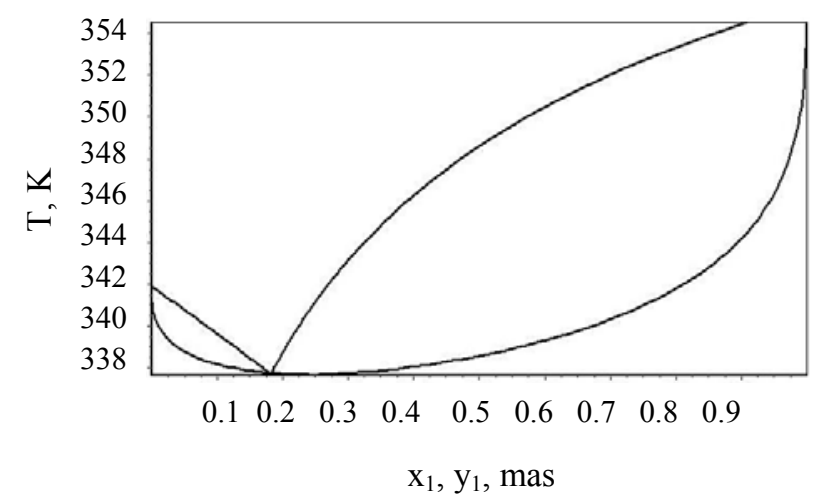

Fig. 4b. Liquid-vapor phase diagram of 2-propanol* hexane system

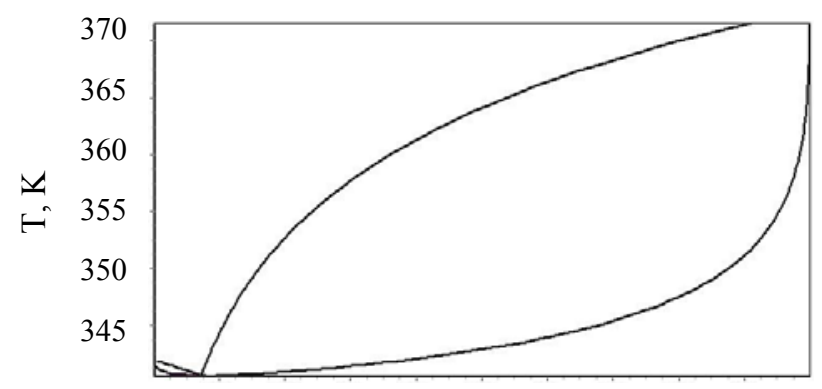

$\begin{array}{lllllllll}0.1 & 0.2 & 0.3 & 0.4 & 0.5 & 0.6 & 0.7 & 0.8 & 0.9\end{array}$

$\mathrm{x}_{1}, \mathrm{y}_{1}$, mas

Fig. 5b. Liquid-vapor phase diagram of 2-butanol* hexane system.

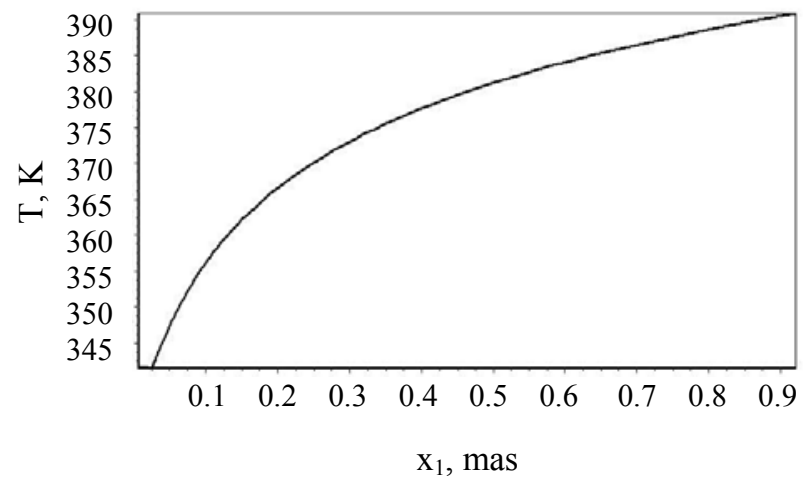

Fig. 6b. Liquid-vapor phase diagram of 2-pentanol* hexane system 


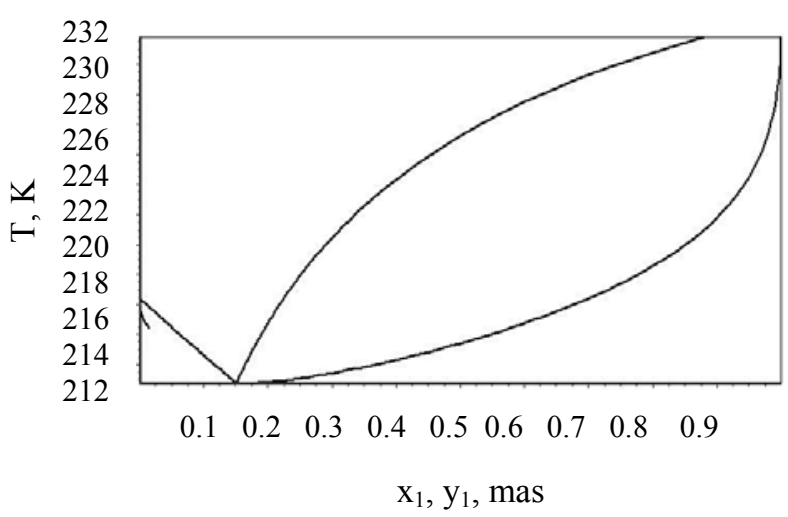

Fig. 7a. Liquid-solid phase diagram of 2-octanol* octane system.

\section{CONCLUSIONS AND RECOMMENDATIONS}

Models for the enthalpy of melting and enthalpy of evaporation, as well as the melting point and boiling point, make it possible to calculate the phase diagrams of systems based on secondary alcohols in the absence of information or the presence of incomplete data on the properties of pure components. The results of the calculation given in the table are in agreement with the experimental data [16].

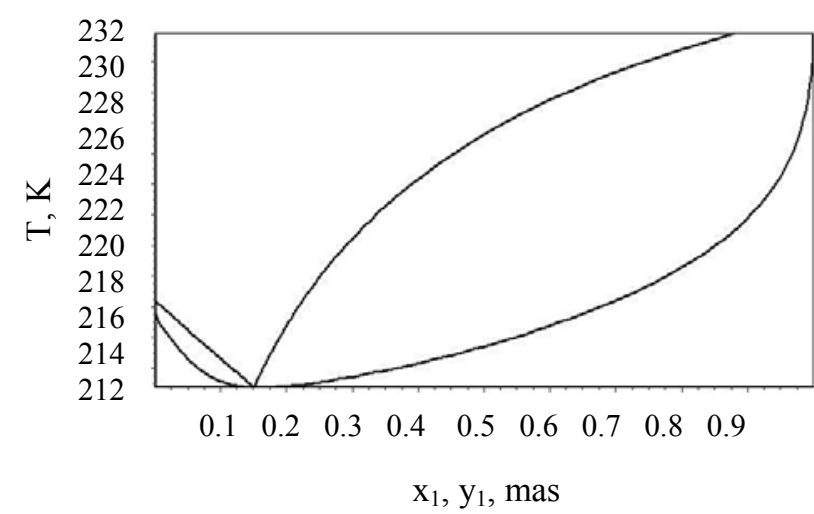

Fig. 7b. Liquid-vapor phase diagram of 2-octanol* octane system

The minimum eutectic temperature (formation of the solid phase) of the mixtures of secondary alcohols and alkanes studied is $-62.4^{\circ} \mathrm{C}$ (2-octanol - octane), which is below the cold filter plugging point for cold $\left(-20^{\circ} \mathrm{C}\right)$ and arctic $\left(-38^{\circ} \mathrm{C}\right)$ climate. Thus, there is no obstacle to the creation of fuel compositions in order to control the flammability of diesel fuels and other purposes.

\section{REFERENCES}

1. Moreau A., Segovia J.J., Bermejo M.D., and Martín M.C. Characterizing second generation biofuels: Excess enthalpies and vapourliquid equilibria of the binary mixtures containing 1-pentanol or 2-pentanol and n-hexane. Fluid Phase Equilibria, 2016, vol. 425, pp. 177-182. DOI: 10.1016/j.fluid.2016.05.031.

2. Moreau A. Thermodynamic Characterization of Environmentally Sustainable Fuels: Experimental Determination of the Vapor-liquid Equilibrium and the Excess Enthalpies for Mixtures of Interest to the Development of Biogasolines, PhD Thesis, University of Valladolid, Spain, 2015.

3. Moreau A., Martín M.C., Chamorro C.R., and Segovia J.J. Thermodynamic characterization of second generation biofuels: Vapourliquid equilibria and excess enthalpies of the binary mixtures 1-pentanol and cyclohexane or toluene. Fluid Phase Equilibria, 2012, vol. 317, pp. 127-131. DOI: 10.1016/j.fluid.2012.01.007.

4. Moreau A., Martín M.C., Aguilar F., and Segovia J.J. Vapour-liquid equilibria and excess enthalpies of the binary mixtures 1-pentanol with 2,2,4-trimethylpentane or $n$-heptane. Fluid Phase Equilibria, 2013, vol. 338, pp. 95-99. DOI: 10.1016/j.fluid.2012.11.005.

5. Moreau A., Segovia J.J., Villamanan R.M., and Martín M.C. Thermodynamic behaviour of second generation biofuels: Vapour-liquid equilibria and excess enthalpies of the binary mixtures 2-pentanol and $n$-heptane or 2,2,4-trimethylpentane. Fluid Phase Equilibria, 2014, vol. 384, pp. 89-94. DOI: 10.1016/j.fluid.2014.10.016.

6. Moreau A., Segovia J.J., Rubio J., and Martín M.C. Thermodynamics properties, VLE and $\mathrm{H}^{\mathrm{E}}$, of the systems 2-pentanol and cyclohexane or methylbenzene for contributing to the knowledge of new biofuels Fluid Phase Equilibria, 2016, vol. 409, pp. $92-97$. DOI: 10.1016/j.fluid.2015.09.035.

7. Peng C., Liu H., and Hu Y. Solid-liquid equilibria based on an equation of state for chain fluids. Fluid Phase Equilibria, 2001 , vol. 180, pp. 299-311. DOI: 10.1016/S0378-3812(01)00369-7.

8. Collinet E. and Gmehling J. Activity coefficient at infinite dilution, azeotropic data, excess enthalpies and solid-liquid-equilibria for binary systems of alkanes and aromatics with esters. Fluid Phase Equilibria, 2005, vol. 230, pp. 131-142. DOI: $10.1016 /$ j.fluid.2004.12.005.

9. Lei Z., Chen B., Li C., and Liu H. Predictive Molecular Thermodynamic Models for Liquid Solvents, Solid Salts, Polymers, and Ionic Liquids. Chemical Reviews, 2008, vol. 108, no. 4, pp. 1419-1455. DOI: 10.1021/cr068441+.

10. Kontogeorgis G.M., Tsivintzelis I., Michelsen M.L., and Stenby E.H. Towards predictive association theories. Fluid Phase Equilibria, 2011, vol. 301, pp. 244-256. DOI: 10.1016/j.fluid.2010.11.025.

11. Esina Z.N., Korchuganova M.R., and Murashkin V.V. Matematicheskoe modelirovanie fazovogo perekhoda zhidkost' - tverdoe [Mathematical simulation of phase change fluid - solid]. Vestnik TGU. Upravlenie, vychislitel'naya tekhnika i informatika [Tomsk State University Journal of Control and Computer Science], 2011, no. 3(16), pp. 13-23.

12. Korchuganova M.R., Esina Z.N., and Murashkin V.V. Vozmozhnosti modeli PCEAS dlya rascheta fazovykh ravnovesiy zhidkost'tverdoe i zhidkost'-par pri postoyannom davlenii [Features of the PCEAS model for the calculation of liquid-solid and liquid-vapor phase equilibria at constant pressure]. Izvestiya vuzov. Seriya: Khimiya i khimicheskaya tekhnologiya [Russian journal of chemistry and chemical technology], 2014, vol. 57, no. 1, pp. 43-46.

13. Esina Z.N., Murashkin V.V., and Korchuganova M.R. Phase Chart Eutectic and Azeotropic System (PCEAS). Certificate of state registration of software no. 2012618394 (RU), 2012.

14. Esina Z.N., Murashkin V.V., Korchuganova M.R. Phase Chart Eutectic and Azeotropic System (PCEAS). Certificate of state registration of software no. 2012620983 (RU), 2012. 
15. Kogan V.B. Geterogennye ravnovesiya [Heterogeneous equilibria]. St. Petersburg: Khimiya Publ., 1968. 432 p.

16. Ogorodnikov S.K., Lesteva T.M., and Kogan V.B. (ed.) Azeotropnye smesi [Azeotropic mixtures]. St. Petersburg: Khimiya Publ., 1971. $849 \mathrm{p}$.

Zoya N. Esina

Cand.Sci.(Eng.), Senior Researcher, Kemerovo State University, Kemerovo, Russian Federation

Alexander M. Miroshnikov

Dr.Sci.(Eng.), Professor, Kemerovo Institute of Food Science and Technology (University), Kemerovo, Russian Federation

Margarita R. Korchuganova

Teacher MBNOU “City Classical Lyceum”, Kemerovo, Russian Federation 